\title{
The Effects of Technical Chlordane on Energy Metabolism of Bacillus subtilis
}

\author{
By R. WIDDUS, * P. W. TRUDGILL AND M. J. MALISZEWSKI \\ Department of Biochemistry and Agricultural Biochemistry, \\ University College of Wales, Aberystwyth, SY23 3 DD
}

(Accepted for publication 10 August I97I)

\begin{abstract}
SUMMAR Y
When crude membrane preparations from broth-grown Bacillus subtilis (ATCC 9372) were incubated with 20 p.p.m. technical chlordane inhibition of NADH oxidase reached $45 \%$ in only $3 \mathrm{~min}$. and $75 \%$ after I h. Maximum inhibition was obtained at this concentration of chlordane. NADH:acceptor oxidoreductase (EC I.6.99.-) of membrane preparations was insensitive to 20 p.p.m. chlordane. Disruption of the remainder of the electron-transport chain appeared to be general though more severe in the region between NADH dehydrogenase and cytochrome c. A generalized assay for ATPases revealed no sensitivity to chlordane over a concentration range 20 to IOO p.p.m. and a pre-incubation period of $I \mathrm{~h}$. The inhibition of TCA cycle enzymes observed, subsequent to the incubation of high-speed supernatant fluid with 20 p.p.m. chlordane, extended the range of chlordane-sensitive phenomena to enzymes other than those that are membrane bound.
\end{abstract}

\section{INTRODUCTION}

The growth of a range of Gram-positive bacteria is inhibited by technical chlordane (Trudgill \& Widdus, 1970). Growing cultures of Bacillus subtilis (ATCC9372) treated with 20 p.p.m. technical chlordane ceased to grow and displayed a rapid decline in respiration rate (Trudgill, Widdus \& Rees, 1971). The inhibition by organochlorine insecticides of metabolic activities associated with respiration has been reported by several workers. Saklin, Terriere \& Remmert (I955) demonstrated the almost complete inhibition of TCA cycle activity of housefly homogenates by DDT at 18 p.p.m. Their suggestion that oxidative phosphorylation was also directly inhibited seemed doubtful in view of the near constant $\mathrm{P} / \mathrm{O}$ ratios obtained over a range of DDT concentrations. Johnston (195I) observed the inhibition of rat heart succinoxidase by DDT at 35 p.p.m. though transport of electrons from succinate to triphenyltetrazolium chloride was unaffected. Morrison \& Brown (1954) reported the inhibition of cytochrome oxidase of the American cockroach by $\alpha$ and $\gamma$-chlordane, aldrin and heptachlor at 400 p.p.m.; endrin at 32 p.p.m. was inhibitory to this enzyme in catfish (Colvin \& Phillips, I968). Wineley \& San Clemente (1970) reported the inhibition of cytochrome $c$ oxidase activity of Nitrobacter agilis extracts by chlordane and heptachlor at 500 p.p.m.

$\mathrm{Na}-\mathrm{K}$ and $\mathrm{Mg}$-ATPases of rat brain homogenates and insect tissues were inhibited by organochlorine insecticides including chlordane and DDT (Koch, I969a, $b$; Koch, Cutkomp \& Do, 1969; Patil, Matsumura \& Bratkowski, 1969) which may in part be responsible for the disruptive effects which these compounds have on nervous transmission. Similar ATPase enzymes were responsible for ion transport and perhaps oxidative phosphorylation in bacteria.

* Present address: Centre for Theoretical Biology, State University at Buffalo, New York I4226, U.S.A. 
In the present paper we report results from the study of the effects of technical chlordane upon these respiration and energy associated metabolic activities of chlordane-sensitive Bacillus subtilis (ATCC9372).

\section{METHODS}

Organisms. Bacillus subtilis (ATCC9372) was obtained from the National Collection of Industrial Bacteria, Aberdeen. Stock cultures were maintained on nutrient agar slopes.

Growth media. Organisms were grown in liquid culture on nutrient broth (Oxoid Ltd., London) at $30^{\circ}$ and $200 \mathrm{rev}$. $\mathrm{min}$. on a New Brunswick gyrotary shaker (New Brunswick Scientific Co., New Brunswick, New Jersey, U.S.A.).

Harvesting and disruption of bacteria. Bacteria were harvested from liquid culture by centrifuging at $25,000 \mathrm{~g}$ for $15 \mathrm{~min}$. and washed by resuspension in the appropriate buffer. Washed bacteria resuspended in buffer $\left(1 \cdot 5 \times\right.$ cell vol.) were disrupted by exposure at $0^{\circ}$ to the output of a Dawe soniprobe, type $7530 \mathrm{~A}$ (Dawe Instruments Ltd, London) for a suitable period or by passage through a French pressure cell with a pressure difference at the orifice of $20,000 \mathrm{lb}$./in. ${ }^{2}$.

Preparation of crude extracts. Broken bacterial suspensions were centrifuged at $0^{\circ}$ and $25,000 \mathrm{~g}$ for $\mathrm{I} 5 \mathrm{~min}$. The supernatant fluid and loose pellet fraction were decanted and subjected to further centrifugal fractionation.

Preparation of high-speed supernatant fluid and membrane fraction. The supernatant-loose pellet fraction from the $25,000 \mathrm{~g}$ centrifugation was centrifuged at $\mathrm{I} 25,000 \mathrm{~g}$ and $2^{\circ}$ for $\mathrm{I} \mathrm{h}$. The clear supernatant fluid was decanted and used for experiments with soluble enzymes; the pellet washed by resuspension in a suitable buffer followed by further centrifugation at I25,000 $\mathrm{g}$ was designated the crude membrane fraction and used for assay of cytochrome mediated respiration and ATPase activities.

Protein estimations. The protein content of extracts and membrane fractions was determined by the modified biuret procedure of Gornall, Bardawill \& David (I949).

Measurement of respiratory activities. Respiratory activities of crude membrane fragments were assayed as follows. NADH oxidase, the stimulation of $\mathrm{O}_{2}$ consumption that occurred when $2 \mu$ mole NADH were added to a $3 \mathrm{ml}$. reaction volume that contained I to $2 \mathrm{mg}$. of membrane preparation and phosphate buffer $(\mathrm{O} \cdot \mathrm{I} \mathrm{M}, \mathrm{pH} 7 \cdot \mathrm{I})$ was followed with a Clark-type oxygen electrode in an agitated vessel maintained at $30^{\circ}$ (Oxygen Monitor, model 53; Yellow Springs Instrument Co., Inc., Yellow Springs, Ohio); NADH: acceptor oxidoreductase (EC I 6.99.-), the procedure of King \& Howard (1967) was used in which the NADHstimulated reduction of 2,6-dichlorophenolindophenol by a suitable amount of membrane fraction was followed spectrophotometrically at $600 \mathrm{~nm}$. and $\mathrm{pH} 8.5$ (0. I M-tris- $\mathrm{HCl}$ buffer) under anaerobic conditions; NADH:triphenyltetrazolium chloride (TTZ) oxidoreductase, this activity roughly corresponding to NADH $\rightarrow$ cytochrome $c$ oxidoreductase in most microorganisms (Brodie, I955) was assayed by estimation of the coloured formazan produced upon reduction of TTZ. Anaerobic incubation mixtures contained, in final vol. $3 \mathrm{ml}$.: I to $5 \mathrm{mg}$. membrane preparation, $0.45 \mu$ mole of TTZ and phosphate buffer $\mathrm{pH} 7 \cdot \mathrm{I}$. Reactions at $30^{\circ}$ were started by addition of $3 \mu \mathrm{mol} \mathrm{NADH}$ and terminated by addition of $5 \mathrm{ml}$. acetone and $5 \mathrm{ml}$. light petroleum (b.p. $40^{\circ}$ to $60^{\circ}$ ), the formazan was then extracted into the organic layer by agitation and its extinction measured at $485 \mathrm{~nm}$. Reduced tetramethylphenylenediamine (TMPD) oxidase: reduced TMPD is known to donate electrons to the cytochrome $c$ region of mitochondrial electron transport chains (Jacobs, I960; Packer \& Jacobs, 1962) and may thus be used to estimate cytochrome $c$ oxidase activity. The oxidation of TMPD, reduced by addition of a minimum amount of $\mathrm{Na}$ ascorbate was fol- 
lowed spectrophotometrically at $560 \mathrm{~nm}$. Aerobic cuvettes contained, in $3 \mathrm{ml}$. reduced TMPD, $0.9 \mu$ mole; membrane fraction, 0.2 to $\mathrm{I} \mathrm{mg}$. protein, and $\mathrm{O} . \mathrm{I} \mathrm{M}$-tris- $\mathrm{HCl}$ buffer $\mathrm{pH} 8 \cdot 0$. Cuvettes in which the membrane preparation was omitted were used to correct for any autoxidation of the reduced TMPD.

Adenosine triphosphatase (ATPase) activities. Membrane-bound ATPase activity was assayed by the method of Harold, Baarda, Baron \& Abrams (1969). Incubation tubes, at $37^{\circ}$, contained in I ml.: $5 \mu$ mole ATP; 5 to Io mg. membrane protein; $5 \mu$ mole $\mathrm{MgCl}_{2} ; \mathrm{O} \cdot \mathrm{I}$ $\mathrm{M}$-tris- $\mathrm{HCl}$ buffer, $\mathrm{pH} 7.5$. Reactions were stopped by adding $\mathrm{I} \mathrm{ml} .10 \%(\mathrm{w} / \mathrm{v})$ trichloroacetic acid. Denatured protein was then removed by centrifugation and the inorganic phosphate released estimated by the method of Fiske \& Subbarow (1925).

Measurement of tricarboxylic acid cycle enzyme activities. With the exception of succinate: acceptor oxidoreductase (EC I.3.99.I), for which the membrane fraction was used, tricarboxylic acid cycle enzymes were assayed spectrophotometrically with suitable dilutions of the high-speed supernatant fluid. The procedures used were: for citrate oxaloacetate lyase (EC 4. I.3 .7; Ochoa, 1955a); for citrate (isocitrate) hydrolyase (EC 4.2 . I .3; Anfinsen,

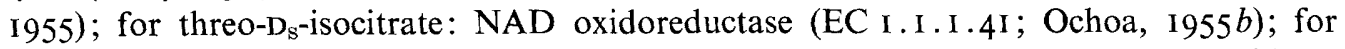
2-oxoglutarate dehydrogenase complex (Kaufman, 1955); for succinate:acceptor oxidoreductase (EC I .3 -99 . I ; Bonner, I955); for L-malate hydrolyase (EC 4.2 . I . 2; Massey, I955); for L-malate: NAD oxidoreductase (EC I I . I.37; Ochoa, I 955 c).

\section{RESULTS}

\section{Effects of chlordane on electron transport by membrane preparations}

When chlordane 20 p.p.m. was given to Bacillus subtilis growing in nutrient broth growth was terminated and the rate of respiration rapidly diminished. Secondary phenomena included a delayed release of incorporated $\left[{ }^{14} \mathrm{C}\right]$ leucine and soluble enzymes in conjunction with a loss of viability and cell lysis (Trudgill et al. 1971).

\section{Table I. The effects of chlordane on respiratory activities of membrane preparations from Bacillus subtilis}

The respiratory chain and sections thereof were assayed as described in the Methods section. Percentage inhibitions are calculated by reference to rates observed with acetone containing controls.

$\begin{array}{lcc}\text { Metabolic activity } & \begin{array}{c}\text { Chlordane } \\ \text { concentration } \\ \text { (p.p.m.) }\end{array} & \begin{array}{c}\text { Inhibition } \\ (\%)\end{array} \\ \text { oxidase } & 20 & 76 \\ \text { oxidase } & 100 & 72 \\ : \text { acceptor oxidoreductase } & 20 & 0 \\ : \text { TTZ oxidoreductase } & 20 & 53 \\ \text { cell respiration } \dagger & 20 & 30 \\ & 20 & 66\end{array}$

* Assay systems were incubated with chlordane for $\mathrm{I} h$. at $30^{\circ}$ prior to addition of substrate.

+ Percentage inhibition of respiration in a growing culture of B. subtilis $1 \mathrm{~h}$. after addition of chlordane From Trudgill et al. I97I.

When crude membrane preparations from Bacillus subtilis were incubated with technical chlordane 20 p.p.m. an initially time-dependent inhibition of NADH oxidase was observed (Fig. I). Only relatively minor increases in the degree of inhibition were obtained upon incubating the membrane preparation with chlordane for periods in excess of 3 min. (Fig. 2). Increases in the amount of chlordane added produced no significant increase in the 
percentage inhibition obtained. Indeed very high levels (500 p.p.m.) were significantly less effective. The demonstrated maximum inhibition at a concentration in the range 20 to 100 p.p.m. (Fig. 2) correlated well with the inhibitory concentrations obtained with growing cultures (Trudgill et al. 1971).

Investigation of the effects of incubation of membrane preparations with technical chlordane upon segments of the electron transport sequence of Bacillus subtilis is shown in Table I. Though the NADH dehydrogenase component was insensitive to chlordane when assayed as an NADH:acceptor oxidoreductase, studies of NADH:TTZ oxidoreductase and reduced TMPD oxidase did, on the basis that both the artificial electron donor and the artificial electron acceptor linked into the electron transport chain at the cytochrome $c$ region, indicated a fairly non-specific but severe inhibition of electron transport throughout the sequence. The maximum inhibition observed with the cell-free systems correlated quite well with the inhibition of respiration observed when whole cells were incubated with chlordane for the same period (Trudgill et al. I97I).

\section{Effect of chlordane on enzymes of the tricarboxylic acid cycle}

Enzymes of the tricarboxylic acid cycle present in I25,000g supernatant fluid from brothgrown Bacillus subtilis were assayed as described in the Methods section. Chlordane effects were tested for by incubation of suitable samples of the supernatant fluid with 20 p.p.m. for I h. Control samples were incubated with parallel samples of acetone and inhibition where observed related to these controls. The results of these experiments are shown in Table 2.

\section{Table 2. The effects of chlordane on activities of TCA cycle enzymes from Bacillus subtilis}

Tricarboxylic acid cycle enzymes of soluble supernatant fluid and membrane fractio
subtilis were assayed as described in the Methods section after incubation for I h. withe
chlordane. Control assays were incubated with acetone.
\[ \begin{array}{cc}\text { Enzyme } & \text { Inhibition } \\ \text { Citrate: oxaloacetate lyase } & 4 \\ \text { Citrate (isocitrate) hydro-lyase } & 39 \\ \text { threo- } D_{\mathrm{S}}-\text { Isocitrate:NADP oxidoreductase } & \text { I8 } \\ \text { 2-Oxoglutarate dehydrogenase complex } & 0 \\ \text { Succinate:acceptor oxidoreductase } & 0 \\ \text { L-Malate hydrolyase } & 8 \\ \text { L-Malate:NAD oxidoreductase } & \text { I6 }\end{array} \]

Contrary to predictions made to anticipate lack of chlordane sensitivity of soluble enzymes, based on a lack of significant inhibition of L-malate:NAD oxidoreductase (EC I.I. I.37) when it was used as an indicator of increased cell permeability (Trudgill et al. 1971), this more thorough investigation showed that L-malate:NAD oxidoreductase and isocitrate: NADP oxidoreductase were significantly inhibited and citrate (isocitrate) hydrolyase to be markedly inhibited by 20 p.p.m. chlordane. It would therefore appear that the provisonal suggestion that inhibition of whole cell respiration by chlordane was entirely due to physical disruption of the cytoplasmic membrane and consequent inhibition of electron transport (Trudgill et al. 1971) may need some modification and extension.

ATPase activity of Bacillus subtilis membranes. Incubation of $\mathrm{Mg}^{2+}$ containing membrane fragments from French pressure cell disrupted $B$. subtilis with chlordane at 20 or 100 p.p.m. did not inhibit ATPase activity (Fig. 3), contrasting with the reported inhibition of $\mathrm{Na}^{+}-\mathrm{K}^{+}$and $\mathrm{Mg}^{2+}$-dependent ATPases of rat-brain homogenates (Koch, 1969a,b) and 
insect tissues (Koch et al. 1969; Patil et al. 1969) by chlorinated insecticides. In spite of the danger of drawing inferences from in vitro systems this lack of sensitivity might be interpreted as indicating that neither energy mediated inorganic ion transport nor oxidative phosphorylation was critically crippled and responsible for the bacteriostasis which rapidly followed administration of chlordane to growing cultures.

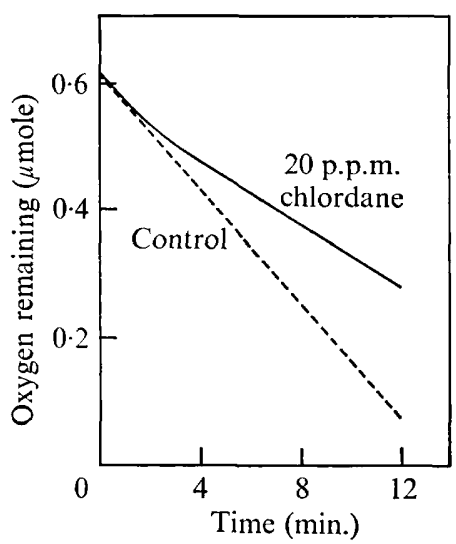

Fig. I

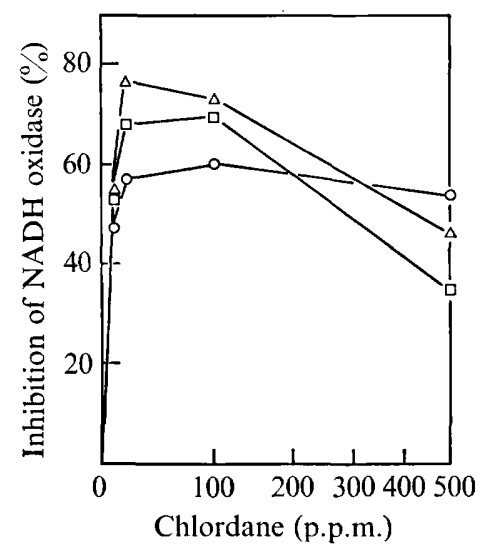

Fig. 2

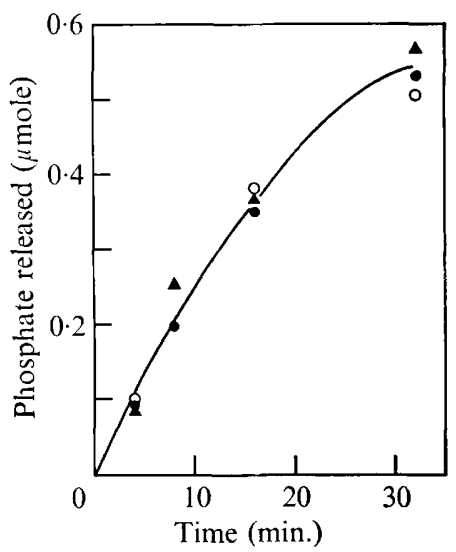

Fig. 3

Fig. I. Time-dependent inhibition of NADH oxidase by technical chlordane. The oxygen monitor reaction vessel contained in vol. $3 \mathrm{ml}$. at $30^{\circ}: 300 \mu$ mole phosphate buffer, $1 \cdot 45 \mathrm{mg}$. membrane protein and $2 \mu$ mole NADH. Chlordane in acetone solution to a final concentration of 20 p.p.m. was added to the reaction at time zero and an equivalent sample of acetone $(5 \mu \mathrm{l}$.) to the control.

Fig. 2. Effects of chlordane concentration and preincubation period on NADH oxidase of Bacillus subtilis. Samples of a suitably diluted membrane preparation were incubated at $30^{\circ}$ in the presence of the indicated amounts of chlordane; $3 \mathrm{ml}$. samples were withdrawn at $3(O-O), 30(\square-\square)$, and $60(\triangle-\triangle)$ min. and NADH oxidase activity assayed as described for Fig. I. Percentage inhibitions were calculated by comparison with acetone treated controls.

Fig. 3. Effect of chlordane on Mg-ATPase of Bacillus subtilis. Reaction tubes, set up as described in the Methods section, were incubated with acetone $(O-O), 20$ p.p.m. chlordane $(\boldsymbol{\Delta}-\mathbf{\Delta})$ or 100 p.p.m. chlordane (-) for $\mathrm{I} h$. before reaction was initiated by adding ATP. Reactions were terminated at the times indicated and the inorganic phosphate released estimated.

\section{DISCUSSION}

The marked inhibition of respiration associated with cessation of growth when chlordane at 20 p.p.m. was administered to growing cultures of Bacillus subtilis (Trudgill et al. 197I) is largely reflected in the inhibition of NADH oxidase observed with crude cell-membrane fragments both as regards the rapid onset of inhibition (Fig. I) and the sensitivity of the system (Fig. 2). NADH dehydrogenase of the membranes, measured with 2,6-dichlorophenol-indophenol as electron acceptor, is insensitive to chlordane. This lack of sensitivity may simply reflect disruption of transport chain component interaction which is manifest as an inhibition of NADH oxidase but obviously not applicable to an assay of the first enzyme of the sequence.

According to Brodie (I955), TTZ withdraws electrons from cytochrome chains at a position equivalent to cytochrome $c$. Our results, while not indicating a specific site in Bacillus subtilis, verify that removal is on the $\mathrm{O}_{2}$ side of the vitamin $\mathrm{K}$, since irradiation of membrane preparations with light of $365 \mathrm{~nm}$. which destroys the vitamin $\mathrm{K}$ while doing relatively little damage to flavins (Kashket \& Brodie, 1962) eliminates the NADH:TTZ oxidoreductase 
activity while not significantly affecting the NADH:(acceptor) oxidoreductase. In addition on the assumption that reduced TMPD donates electrons to the B. subtilis electron transport chain at the cytochrome $c$ region, as is known to occur with mitochondria (Jacobs, I960; Packer \& Jacobs, I962), it appears that the inhibitory effect of technical chlordane on electron transport from NADH dehydrogenase to oxygen is of a general nature. Possibly somewhat greater sensitivity is displayed by the NADH dehydrogenase $\rightarrow$ cytochrome $c$ region (Table I).

Some parallel observations have been made by other workers. Wineley \& San Clemente (1970) have reported inhibition of cytochrome $c$ oxidase activity from cell-free systems of Nitrobacter agilis by chlordane and heptachlor at 500 p.p.m. Though the validity of a direct comparison of mitochondrial and bacterial respiratory systems is always questionable it is perhaps more nearly tenable in the case of Bacillus subtilis because the sequences of electron transport components are nearly identical (Hall \& Palmer, I968). Inhibitions of cytochrome oxidases of American cockroach by chlordane (Morrison \& Brown, 1954) and of that of catfish by endrin (Colvin \& Phillips, 1968) parallel our observations, while the insensitive nature of NADH:cytochrome $c$ oxidoreductase from catfish and succinate:triphenyltetrazolium chloride oxidoreductase from rat heart (Johnston, I95I) suggest rather different regional sensitivity of the electron transport chain. Nelson \& Williams (I97I) presented evidence to show that chlordane and other cyclodienes inhibit growth of Saccharomyces cerevisiae by interfering specifically with oxidative metabolism.

Certain benzimidazole compounds are potent uncouplers of oxidative phosphorylation (Beechey, I966). 4,5,6,7-Tetrachloro-2-trifluoromethylbenzimidazole (TTFB) is not only a potent uncoupler but bears some structural similarity to chlordane.<smiles>FC(F)(F)c1nc2c(Cl)c(Cl)c(Cl)c(Cl)c2[nH]1</smiles>

TTFB<smiles>ClC1=C(Cl)C2(Cl)C3C(Cl)C(Cl)CC3C1(Cl)C2(Cl)Cl</smiles>

Chlordane

It is tempting to envisage chlordane acting similarly as an uncoupler but this is, however, unlikely since chlordane does not possess the weakly acidic group necessary for this function (Weinbach \& Garbus, I969). When, for example, the imino hydrogen of TTFB is replaced with a methyl group the uncoupling capability no longer exists (Buchel, Korte \& Beechey, I965).

The marked inhibition of citrate (isocitrate) hydro-lyase (EC 4.2.I.3) and significant inhibition of isocitrate: NADP oxidoreductase and L-malate: NAD oxidoreductase which occur in the presence of 20 p.p.m. chlordane (Table 2) extends the range of possible sensitive sites that may contribute to the observed inhibition of whole cell respiration beyond the limits of membrane associated phenomena. Somewhat analogous results were indicated by the work of Sacklin, Terriere \& Remmert (1955) who observed the inhibition of oxidation of 'mixed bag' of TCA cycle intermediates by homogenized housefly preparations with levels of 2,2,-bis ( $p$-dichlorophenyl)-I,I, I-trichloroethane (DDT) which failed to inhibit electron transport.

Inhibition of Na-K-ATPase and Mg-ATPase activities of rat brain homogenates and insect tissues by organochlorine insecticides including chlordane and DDT have been impli- 
cated as important inhibitory phenomena (Koch, 1969a, b; Koch et al. 1969; Patil et al. 1969). While inhibition of either ATPase in Bacillus subtilis could be potentially disasterous to the organism as a result of disruption of ATP generation or active transport the lack of inhibition observed with crude membrane preparations (Fig. 3) contrasts with the results reported for mammals and insects.

Though marked inhibition of whole cell respiration by technical chlordane is reflected in the observed inhibition of subcellular particle electron transport and further compounded by inhibition of the TCA cycle, these factors alone do not explain the cessation of growth which rapidly follows the administration of chlordane to a growing culture.

Besides respiration and oxidative phosphorylation there are many activities associated with bacterial membranes which could be adversely affected by inhibition or by removal of control resulting from membrane distortion (Op Den Kamp, van Deenen \& Tomasi, 1969). The lack of effect of chlordane upon ATPase activities of isolated membrane fragments, coupled with the continued uptake of $\left[{ }^{14} \mathrm{C}\right]$ leucine by chlordane treated growing cultures (Trudgill et al. 197I) suggests that inhibition of active transport is not the immediate cause of cessation of growth.

It is clearly possible if, as suggested by Ryter (1968), mesosomes of Bacillus subtilis, themselves membranous structures, are involved in translocation of the nuclei during cell division, that a chlordane-induced disruption of membrane integrity could prevent this critical phase of cell division from occurring.

Other membrane associated phenomena, including protein biosynthesis, are also potential targets but with the present conflict concerning membrane structure remaining unresolved (Stoeckenius \& Engelman, 1969) a membrane-based explanation of cyclodiene toxicity to bacteria must be limited by the rather vague phrase 'deformation of structural integrity'.

Our thanks are due to the Velsicol Chemical Corp. for generously supplying us with technical chlordane, to the Science Research Council for supporting one of us (R.W.) with a studentship during this work, to Mr J. S. Rees for expert technical assistance and to Mrs G. Roberts for typing the manuscript.

\section{REFERENCES}

ANFINSEN, C. B. ( 1955). Aconitase from pig heart muscle. In Methods in Enzymology, vol. I, p. 695. Edited by S. P. Colowick and N. O. Kaplan. London: Academic Press.

BEECHEY, R. B. (1966). The uncoupling of respiratory chain phosphorylation by 4,5,6,7-tetrachloro-2trifluoromethylbenzimidazole. Biochemical Journal 98, 284-289.

BonNer, W. (1955). Succinic dehydrogenase. In Methods in Enzymology, vol. I, p. 723. Edited by S. P. Colowick and N. O. Kaplan. London: Academic Press.

Brodie, A. F. (1955). DPNH cytochrome $c$ reductase (bacterial). In Methods in Enzymology, vol. II, p. 693. Edited by S. P. Colowick and N. O. Kaplan. London: Academic Press.

BuChel, K. H., KoRte, F. \& BeEChey, R. B. (I965). Uncoupling of the oxidative phosphorylation in bacteria by NH-acidic benzimidazoles. Angewandte Chemie (International Edition) 4, 788-789.

Colvin, H. J. \& Phillips, A. T. (1968). Inhibition of electron transport and cholinesterases by endrin. Bulletin of Environmental Contamination and Toxicology 3, I06-I I5.

Fiske, C. H. \& Subbarow, Y. (1925). The colorimetric determination of phosphorus. Journal of Biological Chemistry 66, 375 .

Gornall, A. G., Bardawill, C. J. \& David, M. M. (1949). Determination of serum protein by means of the biuret reaction. Journal of Biological Chemistry $\mathbf{1 7 7}, 75 \mathrm{I}-766$.

HALl, D. O. \& PALMER, J. M. (1968). Mitochondrial research today. Nature, London 221, 717-723.

Harold, F. M., BAARdA, J. R., BARON, C. \& ABrams, A. (I969). Inhibition of membrane-bound adenosine triphosphatase and of cation transport in Streptococcus faecalis by $N, N^{\prime}$-dicyclohexylcarbodimide. Journal of Biological Chemistry 244, 226I-2268. 
JACOBs, E. E. (1960). Phosphorylation coupled to electron transport initiated by substituted phenylenediamines. Biochemical and Biophysical Research Communications 3, 536-539.

Johnston, C. D. (195I). The in vitro effect of DDT and related compounds on the succinoxidase system of rat heart. Archives of Biochemistry and Biophysics 31, 375-382.

KASHKET, E. R. \& BRodiE, A. F. (I962). Effects of near-ultraviolet irradiation on growth and oxidative metabolism of bacteria. Journal of Bacteriology $\mathbf{8 3}$, I094-1 100.

KAUFMAN, S. (I955). $\alpha$-Ketoglutaric dehydrogenase system and phosphorylating enzyme from heart muscle. In Methods in Enzymology, vol. I, p. 714 . Edited by S. P. Colowick and N. O. Kaplan. London: Academic Press.

KING, T. E. \& Howard, R. L. (1967). Preparations and properties of soluble NADH dehydrogenases from cardiac muscle. In Methods in Enzymology, vol. x, p. 275. Edited by R. W. Estabrook and M. E. Pullman. London: Academic Press.

KоCH, R. B. (1969a). Chlorinated hydrocarbon insecticides: inhibition of rabbit brain ATPase activities. Journal of Neuro-chemistry 16, 269-27I.

$\mathrm{KocH}$, R. B. (I969 b). Inhibition of animal tissue ATPase activities by chlorinated hydrocarbon insecticides. Chemical Biological Interactions I, I99-209.

Косн, R. B., CutкомP, L. K. \& Do, F. M. (I969). Chlorinated hydrocarbon insecticide inhibition of cockroach and honey bee ATPases. Life Sciences 8, 289-297.

MASSEy, V. (1955). Fumerase. In Methods in Enzymology, vol. I, p. 730. Edited by S. P. Colowick and N. O. Kaplan. London: Academic Press.

Morrison, P. E. \& Brown, A. W. A. (1954). The effects of insecticides on cytochrome oxidase obtained from the American cockroach. Journal of Economic Entomology 47, 723-730.

Nelson, B. D. \& Williams, C. (1971). Action of cyclodiene pesticides on oxidative metabolism in the yeast Saccharomyces cerevisiae. Journal of Agricultural and Food Chemistry 19, 339-341.

OсHOA, S. (I955a). Crystalline condensing enzyme from pig heart. In Methods in Enzymology, vol. I, p. 687. Edited by S. P. Colowick and N. O. Kaplan. London: Academic Press.

OCHOA, S. (1955b). Isocitric dehydrogenase system (TPN) from pig heart. In Methods in Enzymology, vol. I, p. 699. Edited by S. P. Colowick and N. O. Kaplan. London: Academic Press.

OchOA, S. (1955c). Malic dehydrogenase from pig heart. In Methods in Enzymology, vol. I, p. 736. Edited by S. P. Colowick and N. O. Kaplan. London: Academic Press.

Op Den Kamp, J. A. F., van Deenen, L. L. M. \& Tomasi, V. (1969). In Structure and Functional Aspects of Lipoproteins in Living Systems, p. 227. Edited by E. Tria and A. M. Scanu. London: Academic Press.

PACKer, L. \& JACOBS, E. E. (1962). Coupling of phosphorylation to terminal segments of the mitochondrial respiratory chain. Biochemica et biophysica acta 57, 37 I-373.

Patil, K. C., Matsumura, F. \& Bratkowski, T. A. (1969). Brain ATPases of the resistant and susceptible German cockroach. Journal of Economic Entomology 62, I502-1503.

Ryter, A. (1968). Association of the nucleus and the membrane of bacteria: a morphological study. Bacteriological Reviews 32, 39-54.

Saklin, J. A., Terriere, L. C. \& Remmert, L. F. (1955). Effect of DDT on enzymatic oxidation and phosphorylation. Science, New York I22, 377-378.

Stoeckenius, W. \& Engelman, D. M. (1969). Current models for the structure of biological membranes. Journal of Cell Biology 42, 613-646.

TRudgill, P. W. \& Widdus, R. (1970). Effects of chlorinated insecticides on metabolic processes in bacteria. Biochemical Journal Ir8, 48-49P.

Trudgill, P. W., Widdus, R. \& ReEs, J. S. (197I). Effects of organochlorine insectides on bacterial growth, respiration and viability. Journal of General Microbiology 69, I-I3.

Weinbach, E. G. \& Garbus, J. (I969). Mechanism of action of reagents that uncouple oxidative phosphorylation. Nature, London 221, IOI6-10I8.

Wineley, C. L. \& SAN Clemente, C. L. (1970). Effects of pesticides on nitrite oxidation by Nitrobacter agilis. Applied Microbiology I9, 214-2 I9. 